\title{
Wastewater Pipeline Design in Accordance with Sea-Pipe-Soil Interaction
}

\author{
Ümit Gökkuş ${ }^{1 *}$, Begüm Yurdanur Dağlı ${ }^{2}$, Mehmet Sinan Yıldırım ${ }^{3}$ \\ 1* Professor, Department of Civil Engineering, Manisa Celal Bayar University, Manisa, Turkey \\ ${ }^{2}$ Research Asst.(Dr), Department of Civil Engineering, Manisa Celal Bayar University, Manisa, Turkey \\ ${ }^{3}$ Research Asst.(M.Sc),Department of Civil Engineering, Manisa Celal Bayar University, Manisa, Turkey
}

\begin{abstract}
After the treatment of the wastewaters, a pipeline is used to transfer the treated water from the onshore pump station to the wastewater disposal marine environment. This technique is required for the dilution process in the marine environment instead of a secondary treatment. When the pipeline design for wastewater treatment is implemented, the stability issues of the pipelines must be considered because the pipeline design is based on factors such as currents, waves, geotechnical conditions, physical properties of the water and pipe's material characteristics. At this point, a computer program is beneficial for the quick design of wastewater pipelines. To find a suitable design under these various design limitation and factors, the algorithm of the SUbmarine Pipeline Design (SUPLID) software was developed which is powerful tool for stability analysis of the submarine pipeline against dynamic current-wave motions and foundation characteristics. The SUPLID program provides a flexible design environment for the design engineer for dimensioning and stabilizing the pipeline system with also artificial weights. In this study, the main methodology and the structure of the SUPLID program was introduced and one of its application for a typical submarine wastewater pipeline was discussed.
\end{abstract}

Keywords: Wastewater pipelines, computer-aided design of sub-sea pipes, sea-pipe-soil interaction, stabilization of sub-sea pipes

\section{INTRODUCTION}

In recent years, it was seen that, the submarine pipelines play an important role in the field of oil, gas transmission and municipal and industrial wastewater disposing in marine environment or even, cooling water inlet and outlet systems in industrial facilities close to marine environment. At this point implementation of the submarine pipelines for wastewater disposal is a popular treatment technique. Generally, offshore discharge diffuser systems are used for disposing urban and industrial liquid waste. Dilution of these wastewater transported to the disposed environment is achieved by the diffuser systems reducing the fluid velocity. A diffuser also increases the pressure of the conveying fluid inside the pipeline. Submarine outfalls are generally composed of an onshore headwork, a feeder pipeline and a diffuser system at its end [3],[8],[9]. Software implementation is implemented in many areas of the wastewater disposing projects such as optimizing the disposed wastewater amount, performing hydraulic calculations, performance modelling, network and equipment logging, repair planning, accounting and billing, dispatch control and operating management optimization such as, GIS, In Geo, Mike NET [14]. Beside many software implemented topics, the design methodology of a wastewater pipeline system is demonstrated by many researchers. Ajeesh presented the preliminary analysis of a flexible cold water pipe made up of High Density Polyethylene (HDPE) catering for an island based desalination plant [1]. Preliminary hydrodynamic analysis of the cold water pipeline was carried out using Orca Flex software under regular wave effect. A computer program was implemented (WANDA Transient software) for the transient simulation of water flow in two different pipeline systems [2]. EPANET is a non-commercial software which is used for modeling water distribution piping systems [10]. This computer software package was implemented for analyzing pressurized irrigation systems and also dynamic analysis of many pipe network types. In the light of these mentioned literature, the SUPLID software includes design of the suspended pipelines resting on artificial concrete supports and also surface pipelines freely resting on the sea bottom under the oceanographically, geotechnical conditions and pipe characteristics. SUPLID is consists of sub routines which are DATA, REFRAC (Analysis of wave refraction), BREAKLIN (Determination of Wave Breaking Depth and Height), BURYLIN (Determination of 
Buried Pipe Parts), LINEVDAT (Analysis on Environmental Loads on Buried and Suspended Pipe Portions), CHAPAREN (Wave-Pipe-Soil Interactions) and PIPESTAB (Stabilization of Pipes) [7]. The forces acting on a wastewater discharge pipeline based on the soil, pipe, sea interaction are basically can be analyzed with SUPLID software and the required stabilization procedure can be performed.

This paper presents the solving procedure of computer-aided design for wastewater discharge pipelines to be built in marine environment. The design forces determined in accordance with seapipe-soil interaction are analyzed and the stabilized pipe size and the relevant structural features are obtained for illustrative problem dealt with in case study.

\section{DESIGN PROCEDURE OF SUBMARINE PIPELINES}

General design principles of submarine pipelines require the following stages;

Stage1-4: Determination of: Design parameters considering construction and operation phases; maintenance conditions it's related design parameters; environmental factors influencing the overall design (geotechnical conditions, bathymetry); wind-wave design parameters (to be determined by stochastic processes); parameters related with currents and tides; earthquake effects; onshore locations and capacities of wastewater treatment plant and pump station, Stage 5: Selection of alternative routes in the scope of preliminary study, Stage 6: Performing the oceanographic, bathymetric and geotechnical investigations, Stage 7: Determination of the design parameters for pipeline segments, Stage 8: Performing static and dynamic analysis of the pipeline under environmental and functional loads according to the pipe-soil and pipe-wave and current interactions, Stage 9: Determination of behaviors of pipeline under design loads and elimination of the unfeasible routes, Stage 10: Analyzing economically and comparing construction-operation and maintenance costs and Stage 11:Selection of final route providing the economical and technical constraints By carrying out these stages, the SUPLID software routine can be summarized with the following steps mentioned as below. The flow chart for the submarine pipeline design process (SUPLID main program) is shown in Figure 1.

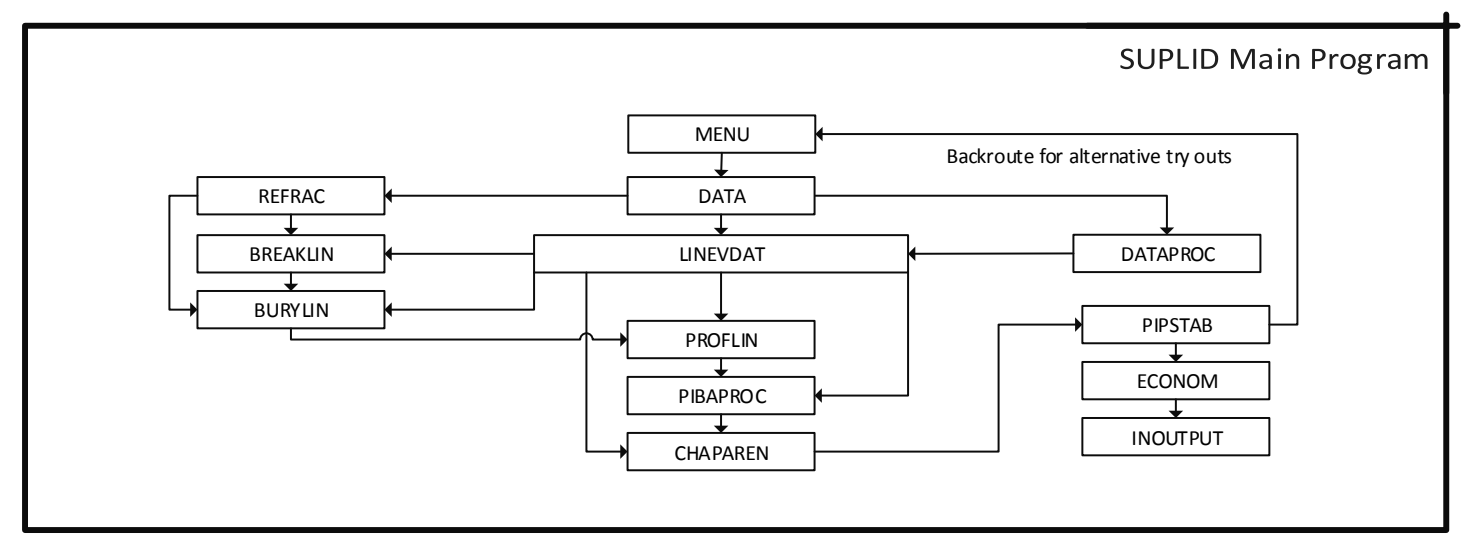

Figure 1: Submarine pipeline design procedure (SUPLID Main Program)

\section{III.IDENTIFICATION OF FORCES AND PIPELINE STABILIZATION}

In the SUPLID program, the pipeline stabilization analysis is performed with considering horizontal and vertical forces acting on the pipeline system. The horizontal interaction forces between water and pipe section are drag forces $\left(\mathrm{F}_{\mathrm{D}}\right)$ caused by moving current-wave water interacting with the pipe, wave-induced inertia forces $\left(\mathrm{F}_{\mathrm{I}}\right)$ resulting from water accelerations in the vicinity of the pipeline [13]. Horizontal forces resulting from the interaction between soil and pipeline and hydrodynamic forces are balanced with the sliding resistance $\left(F_{S}\right)$. The impact force (the interaction between the pipeline and moving external objects) is considered as a horizontal force but this event was not considered in the concept of this study.

$$
\begin{aligned}
& F_{D}=(0.5) \rho D C_{D} a b s(u) \\
& F_{I}=\rho \frac{\pi D^{2}}{4} C_{M} \frac{d u}{d t}
\end{aligned}
$$

where $\rho$ is the sea water density, $C_{D}$ is the wave drag coefficient, $\mathrm{C}_{M}$ is the coefficient of inertia, D is the characteristic length of the structure, $u$ is the velocity of the fluid particle and $\mathrm{du} / \mathrm{dt}$ is the horizontal acceleration of the fluid particle. 
For cohesive soil,

$$
\mathrm{F}_{\mathrm{s}}=\mathrm{F}_{\mathrm{v}} \tan \delta+\frac{1}{2} \gamma_{\mathrm{s}} \mathrm{z}^{2} \tan ^{2}\left(45+\frac{1}{2} \phi\right)
$$

For cohesionless soil,

$$
\mathrm{F}_{\mathrm{s}}=\mathrm{CB}+\left(\frac{1}{2} \gamma_{\mathrm{s}} \mathrm{Z}+2 \mathrm{c}\right) \mathrm{z}
$$

where $\mathrm{z}$ is the depth of the buried part of the pipeline, $\gamma_{S}$ is the saturated unit weight of the soil, $\phi$ is the angle of internal friction, $\mathrm{B}$ is the effective foundation width. The friction angle between the concrete pipe and the ground is $\delta=(2 / 3) \phi$. The principal vertical forces acting on the pipeline are the buoyancy force $\left(\mathrm{F}_{\mathrm{B}}\right)$ resulted from the submergence of pipeline, hydrodynamic lift force $\left(F_{L}\right)$ resulted from the increased flow rate over pipe, pipeline own weight or artificial weight $\left(\mathrm{F}_{\mathrm{W}}\right)$. Particularly, soil bearing capacities $\left(\mathrm{F}_{\mathrm{C}}\right)$ and pullout forces $\left(\mathrm{F}_{\mathrm{O}}\right)$ were not considered in this study [4][5].

$$
\begin{aligned}
& F_{B}=\pi\left(R_{1}^{2}\right) S_{g w}-\pi\left(R_{2}^{2}-R_{1}^{2}\right) S_{g c}-\pi\left(R_{3}^{2}-R_{2}^{2}\right) S_{g i} \\
& -\pi\left(R_{4}^{2}-R_{3}^{2}\right) S_{g p}-\pi\left(R_{4}^{2}\right) S_{g f} \\
& \mathrm{~F}_{\mathrm{L}}=\frac{1}{2} \rho \mathrm{DC}_{\mathrm{L}} \mathrm{u}^{2}
\end{aligned}
$$

For cohesive soil,

$$
\mathrm{F}_{\mathrm{c}}=\left(\mathrm{N}_{\mathrm{q}} \gamma_{\mathrm{s}} \mathrm{z}+\frac{1}{2} \mathrm{~N}_{\gamma} \gamma_{\mathrm{s}} \mathrm{B}\right) \mathrm{B}
$$

For cohesionless soil,

$$
\mathrm{F}_{\mathrm{c}}=\left(\mathrm{N}_{\mathrm{c}} \mathrm{C}_{\mathrm{u}}+\gamma_{\mathrm{s}} \mathrm{z}\right) \mathrm{B}
$$

where $\mathrm{S}_{\mathrm{gw}}, \mathrm{S}_{\mathrm{gc}}, \mathrm{S}_{\mathrm{gi}}, \mathrm{S}_{\mathrm{gp}}$ and $\mathrm{S}_{\mathrm{gf}}$ are denoted as specific weight of the sea water, conveyed fluid, steel pipe, concrete jacket or saddle, insulation layer of pipe. In addition, $\mathrm{R}_{1}, \mathrm{R}_{2}, \mathrm{R}_{3}$ and $\mathrm{R}_{4}$ are represented as the external diameters of pipes, concrete and insulation layers respectively. $\mathrm{C}_{\mathrm{L}}$ is the lift force coefficient, $\mathrm{C}_{\mathrm{U}}$ is the undrained shear stress and $\mathrm{N}_{\mathrm{C}}, \mathrm{Nq}$, and $\mathrm{N}_{\mathrm{S}}$ are soil bearing capacity factors.

\section{III.1. Stabilization process}

The main objective of the stabilization process is to provide the horizontal and vertical equilibrium of submerged pipe section. The sliding effect of summed horizontal forces caused by hydrodynamic drag and inertia forces against lateral soil resistance is balanced with the total vertical forces (hydrostatic buoyancy force, hydrodynamic lift force and artificial weight of pipe jacket or concrete saddle placed at certain intervals along pipeline). The vertical stability of the pipeline should be provided by taking the limit value of soil bearing capacity. The horizontal and vertical force components are shown as follow [12][6].

For surface and suspended pipe,

$F_{V}=F_{W}-F_{B}-F_{L} ; F_{H}=F_{D}+F_{I}$

For artificially protected pipe,

$\mathrm{F}_{\mathrm{V}}=\mathrm{F}_{\mathrm{W}}-\mathrm{F}_{\mathrm{LA}}-\mathrm{F}_{\mathrm{B}}-\mathrm{F}_{\mathrm{Y}}$

For buried pipe,

$F_{V}=F_{W}+W_{C}-F_{B} \quad ; F_{H}=0$

The required safety factors to be taken into account respectively for buoyancy, sliding and over-topping effect are denoted as $\mathrm{S}_{\mathrm{B}}, \mathrm{S}_{\mathrm{S}}$ and $\mathrm{S}_{\mathrm{O}}$ [Sümer et al.,1997]

Stability for buoyancy effect

$\mathrm{S}_{\mathrm{B}}<\left(\mathrm{F}_{\mathrm{C}} / \mathrm{F}_{\mathrm{V}}\right)$

Stability for sliding effect

$\mathrm{S}_{\mathrm{S}}<\mathrm{F}_{\mathrm{V}} \tan (2 \phi / 3) /\left|\mathrm{F}_{\mathrm{S}}+\mathrm{F}_{\mathrm{H}}\right|$

Stability for overtopping effect for saddle)

$\mathrm{S}_{0}<\mathrm{F}_{\mathrm{V}} \mathrm{X}_{\mathrm{b}} / 2 /\left|\mathrm{F}_{\mathrm{HC}} \mathrm{e} / 2+\mathrm{F}_{\mathrm{H}}(\mathrm{e}+\mathrm{D} / 2)\right|$

In the equation above, e is the distance between the pipe and soil surfaces. Length of the saddle in flow direction, wave-current induced horizontal forces acting on saddle and pipe are written as $\mathrm{X}_{\mathrm{b}}, \mathrm{F}_{\mathrm{HC}}$ and $\mathrm{F}_{\mathrm{H}}$. The pipeline laying positions and acting forces are given in Figure 2 for different types of pipeline sections (jacket, conbas, trench and saddle).

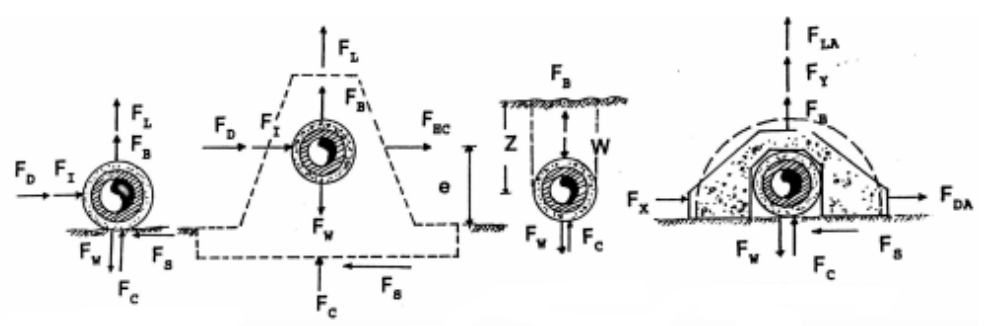


Figure 2: Forces acting on different types of pipelines

III.2. Computer-Aided Design of Submarine Pipelines: Description of SUPLID Program

The SUPLID main program involves twelve sub-programs (modules) such as DATA (Data processing module), DATAPROC (Data processing module), LINEVDAT (Line environmental data module), REFRAC (Wave refraction module), BREAKLIN (Wave breaking module), BURYLIN (Buried pipe analysis module), PROFLIN (Wave profile design module), PIBAPROC (Pipe-bathymetry data Processing), CHAPAREN (Characteristic parameters determination module), PIPESTAB (Pipe stability module), INOUTPUT (Input and output managing module) and ECONOM (Economical analysis of the pipeline route module). Basically, DATA module generates bathymetry files of the investigation site (BATDATA), geotechnical and oceanographic information are processed in ZEMDATA and CURRENT modules, pipeline route coordinates are process in PIPECOOR module. As an example, the flowchart for the DATA subprogram is shown in Figure 3.
DATAPROC module is based on the interpolation process to locate the required data at intersection points of the grid system. The outputs of the DATAPROC module are also sent to the COLDATA (Collecting the design parameters from inputs). LINEVDAT, PIBANEW, PIBAN and PB modules creates the design data corresponding to the grid points with the prevailing environmental conditions at the grid system. The flow chart of the LINEVDAT module is given in Figure 4.

BREAKLIN module calculates the breaking depth and wave height for the considered marine environment determines whether each seapipe segment on line is buried or laid freely on sea bottom. Outputs are placed at T and BD files. The flow chart of the BREAKLIN module is given in Figure 5. REFRAC module is used for ray processing. Wave rays are inserted angularly and intermittently in the grid system and refracted linearly or circularly by bathymetric and hydrodynamic conditions on triangular grid elements. Output values are given in C, PRI and PRX files. The REFRAC module flow chart is given in Figure 6.

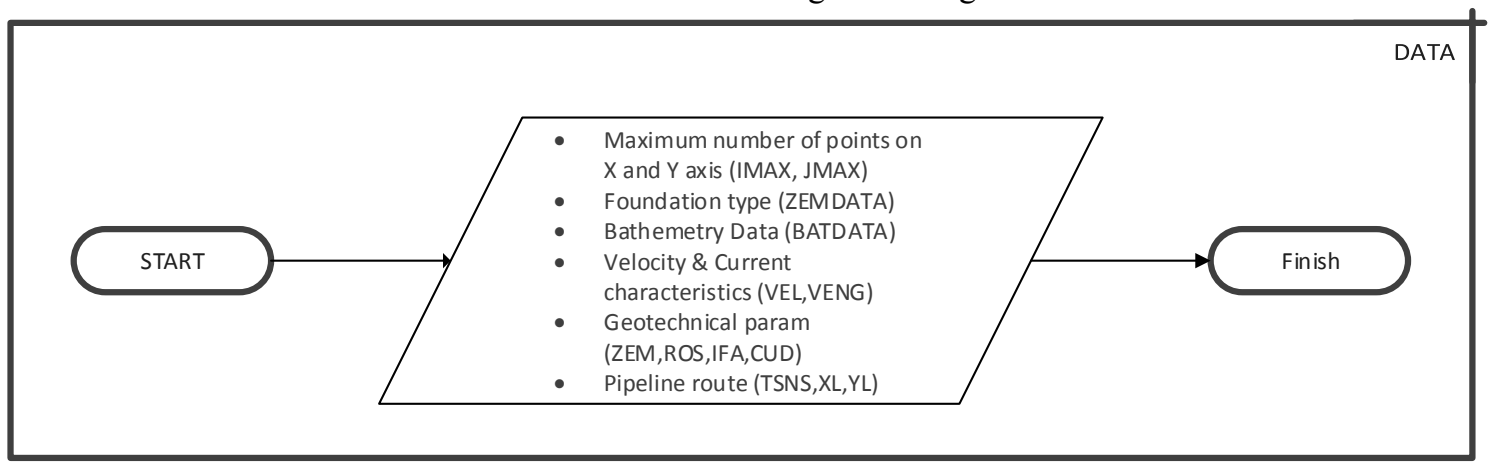

Figure 3: Flow chart of DATA subprogram

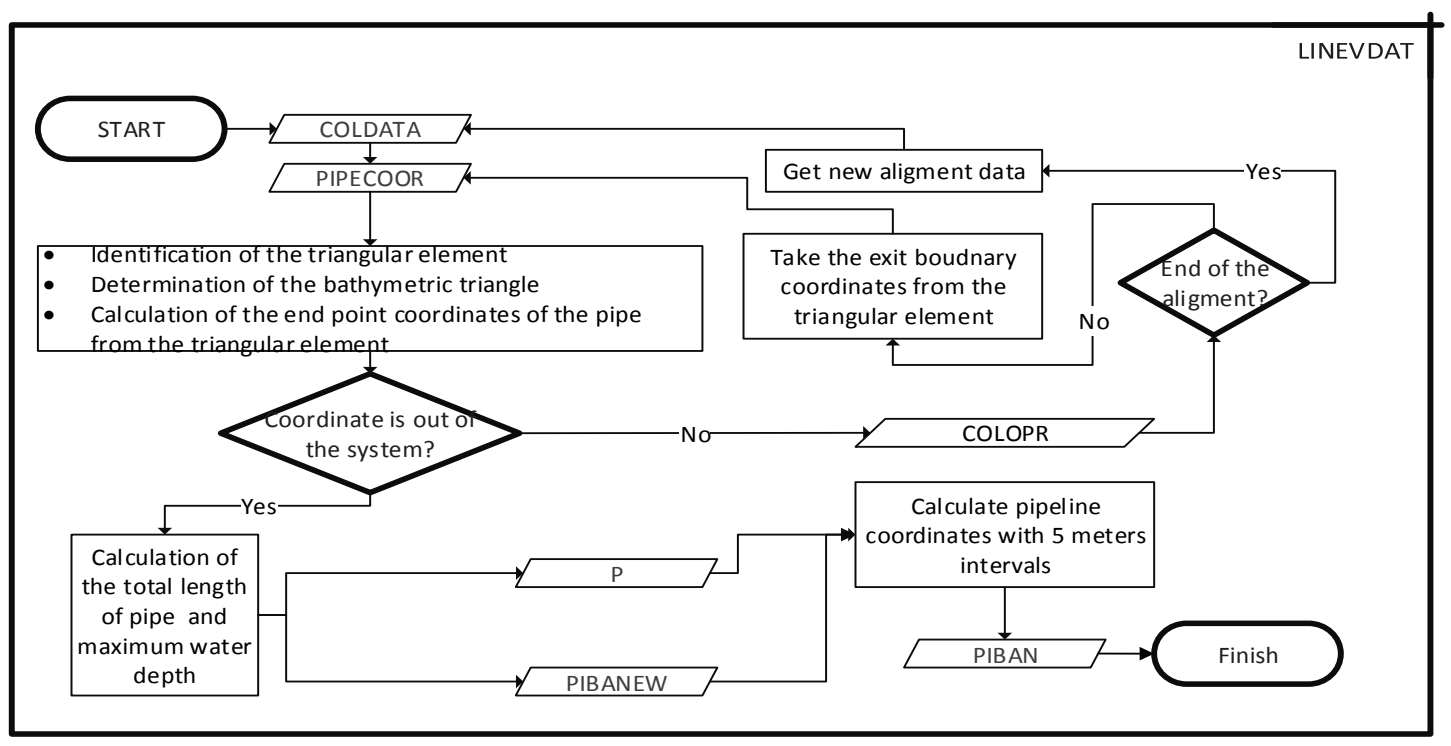

Figure 4: Flow chart of subprogram LINEVDAT. 


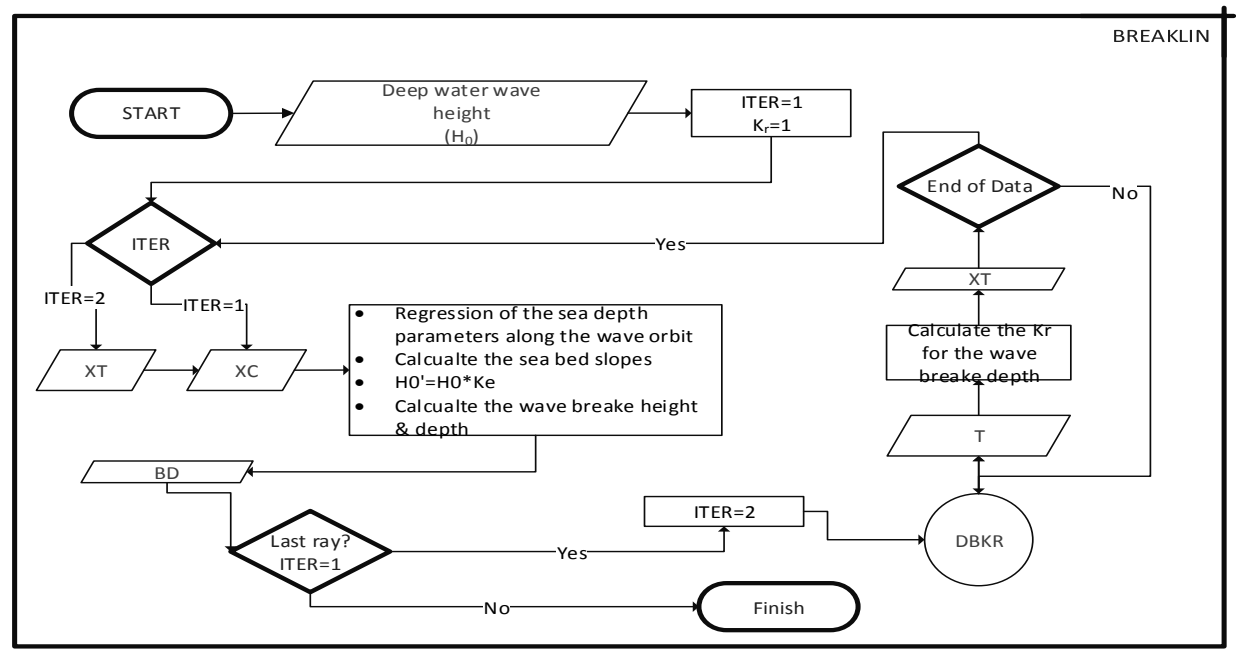

Figure 5: Flow chart of BREAKLIN subprogram

The BURYLIN module uses the PRI, BD and PIBAN files to determine the pipeline branches to be buried. The data composed of the length of buried segments are included in BUR file. The flow diagram of the BURYLIN module is given in Figure 7. PROFLIN module evaluates the outputs of PB and PIBA files and it is interacted with LINEVDAT module. BURYLIN module is responsible for interactively drawing the profile of the pipeline with route alignments. Results of these modules are saved in LINCOR, LINT and LINSURF files. PIBAPROC is the module which considers the data processing related with pipeline and bathymetry interaction. Bottom elevations of each segment on pipeline route are evaluated with PIBANEW and LINT outputs taken from the LINEVDAT module. Similarly elevation for buried pipe determined with PROFLINE module. Wave and current induced pipeline design outputs of each pipe segment are gathered in PRT and BATSURF data files. CHAPAREN is the final module gathering the design data concerning with pipe segments and suitable design types for segments (jacket, conbas, saddle and trench).

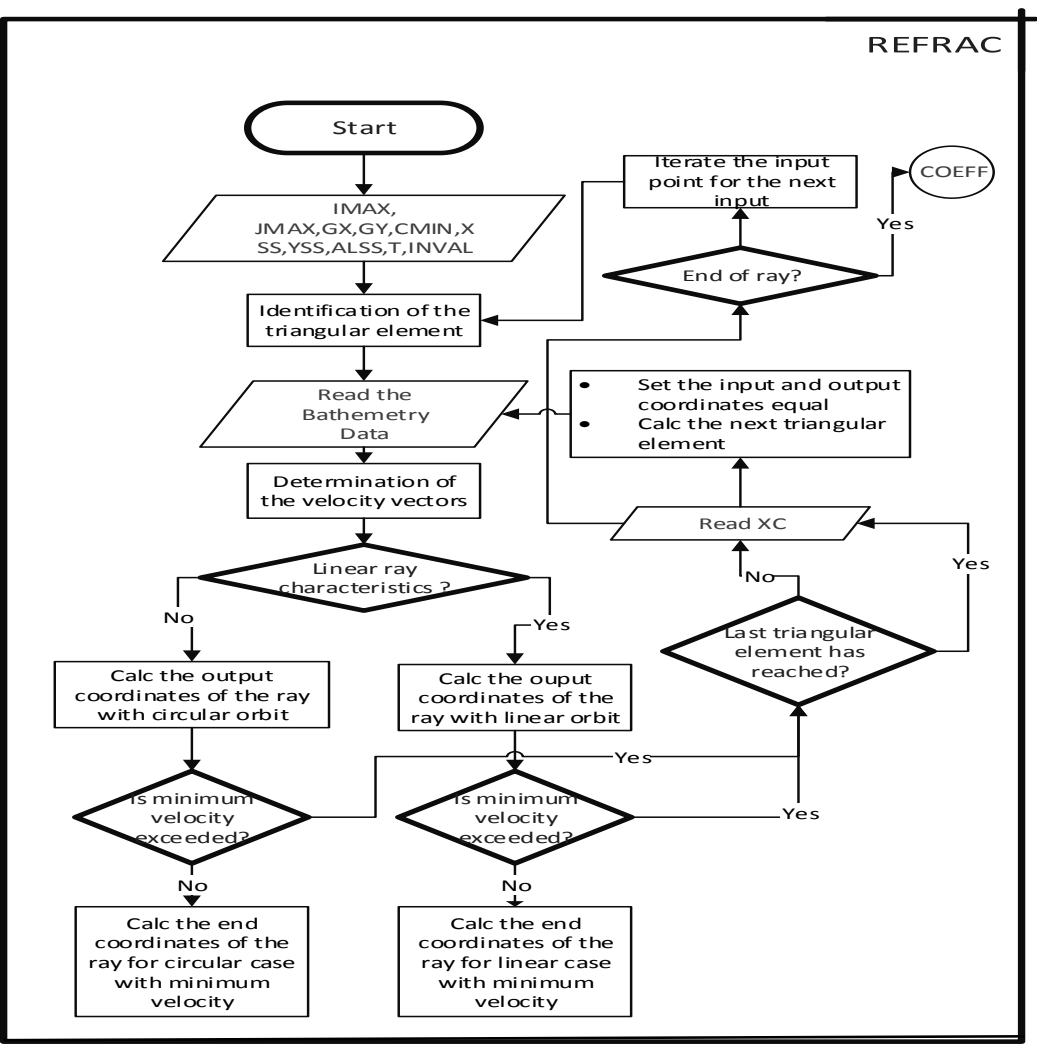


Figure 6: Flow chart of subprogram REFRAC

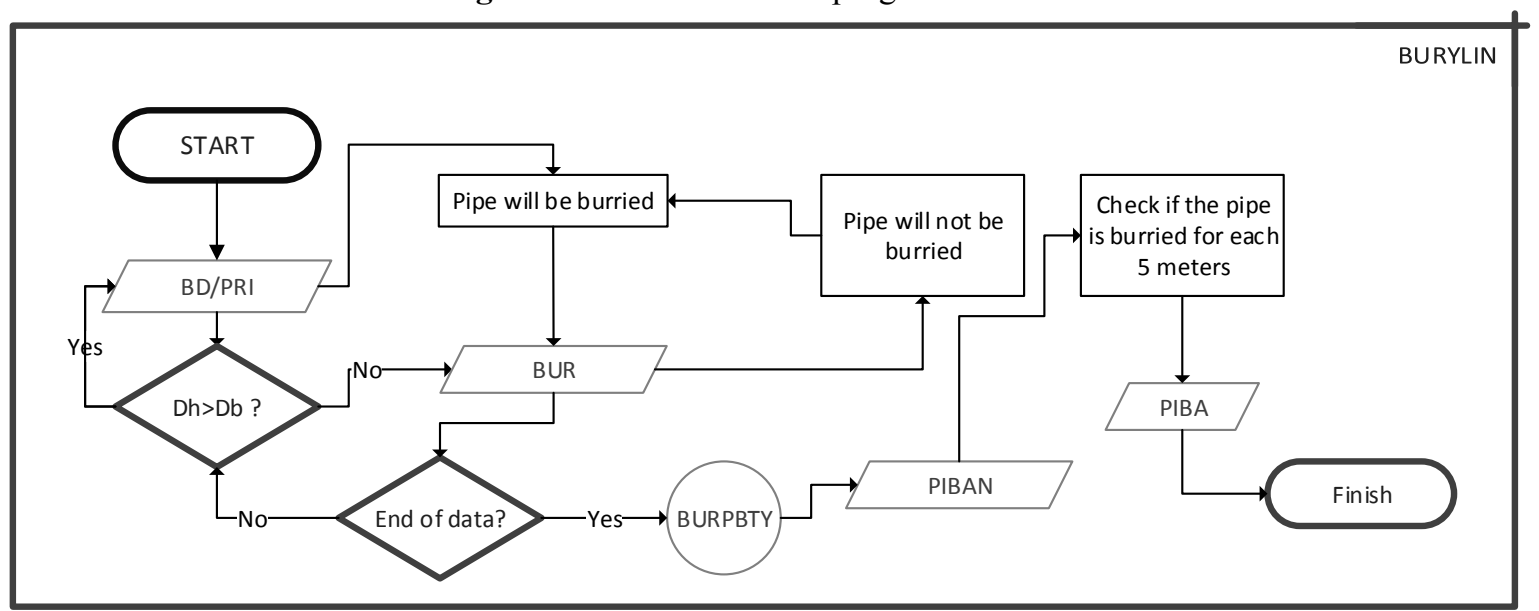

Figure 7: Flow chart of BURYLIN subprogram

PIPSTAB module calculates stability of the pipeline with considering wave and current forces for surface pipes, soil forces for buried pipes. It also considers the pipe operation modes and corresponding hydraulic conditions including the operation, testing and empty pipes and hydraulic with/without wave and currents effects separately and together. The flow diagram of the PIPSTAB module is given in Figure 8.

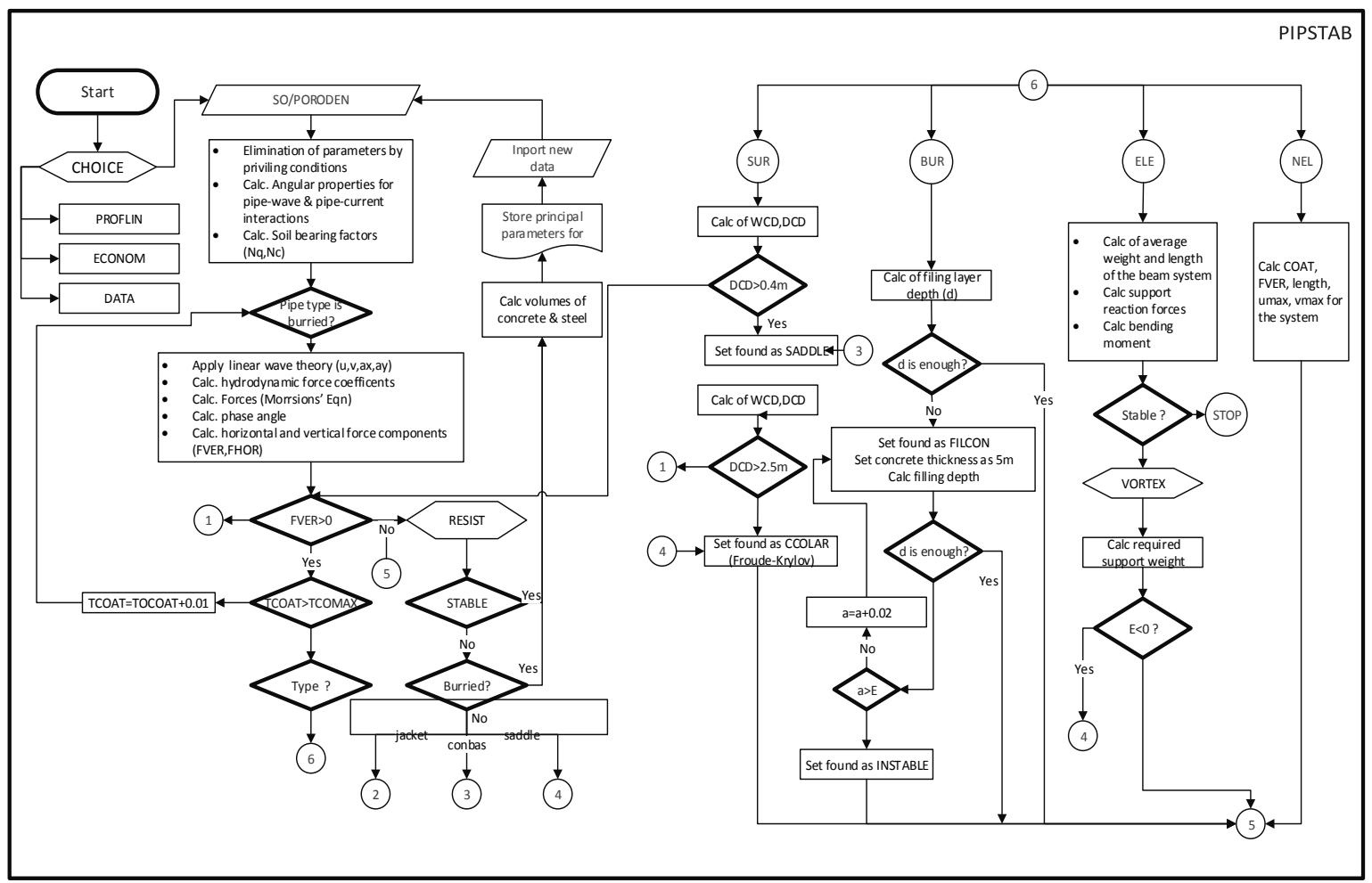

Figure 8: Flow chart of subprogram PIPSTAB

\section{RUNNING OF THE SUPLID}

PROGRAM: A CASE STUDY

The SUPLID program was implemented for the design of the wastewater pipeline system as shown in Figure 9. The $\mathrm{x}$ and $\mathrm{y}$ spans of the coordinates are 200 meters and 100 meters. A typical diffuser system was utilized at the end of the pipe system for disposing the wastewater in the marine environment. 5 meter branches of the pipeline segments were considered for performing the hydrodynamic analysis with considering the wave characteristics. 


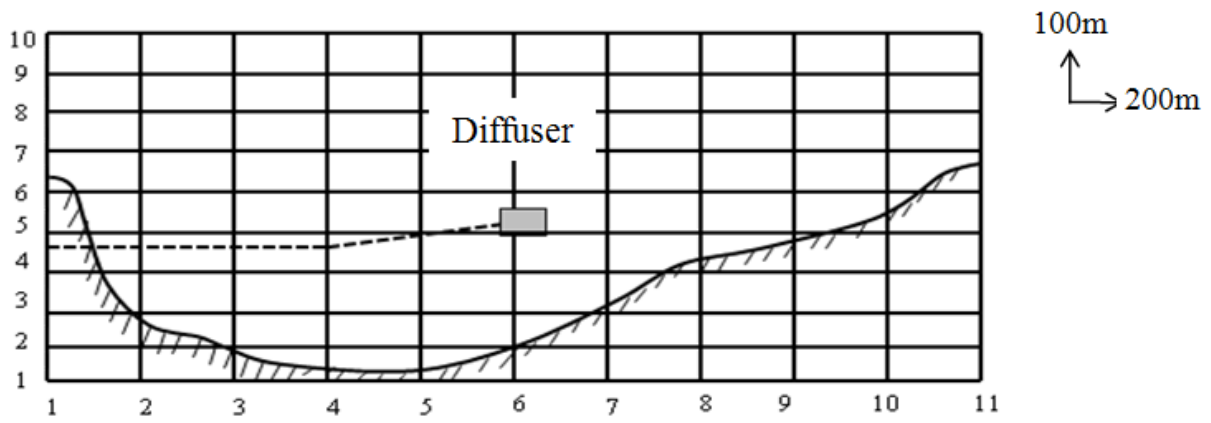

Figure 9: The plan view of the wastewater pipeline system.

The input data of the program is consist of current characteristics at the solution domain with the speed of the current $(\mathrm{Vi})(\mathrm{m} / \mathrm{s})$ and its angular direction (Di) as shown in Table 1. Moreover the bathymetry data of the solution domain used in this case study is provided in Table 2 . In both Table 1 and Table $2,5^{\text {th }}$ and $6^{\text {th }}$ columns were deleted for ease $\mathrm{pf}$ presentation of this paper.

Table 1: Current characteristics along the pipeline route (Speed and angular direction)

\begin{tabular}{|c|c|c|c|c|c|c|c|c|c|c|c|c|c|c|c|c|}
\hline $\mathrm{X} / \mathrm{T}$ & \multicolumn{3}{|c|}{1} & \multicolumn{3}{|c|}{2} & \multicolumn{3}{c|}{3} & \multicolumn{3}{c|}{4} & \multicolumn{3}{c|}{7} & \multicolumn{3}{c|}{8} & \multicolumn{3}{c|}{9} & \multicolumn{2}{c|}{10} \\
\hline & $\mathrm{V} 0$ & $\mathrm{D} 0$ & $\mathrm{~V} 1$ & $\mathrm{D} 1$ & $\mathrm{~V} 2$ & $\mathrm{D} 2$ & $\mathrm{~V} 3$ & $\mathrm{D} 3$ & $\mathrm{~V} 6$ & $\mathrm{D} 6$ & $\mathrm{~V} 7$ & $\mathrm{D} 7$ & $\mathrm{~V} 8$ & $\mathrm{D} 8$ & $\mathrm{~V} 9$ & $\mathrm{D} 9$ \\
\hline 1 & 0 & 0 & 0 & 0 & 0 & 0 & 0 & 0 & 0.5 & 275 & 0.6 & 275 & 0.6 & 275 & 0.7 & 275 \\
\hline 2 & 0 & 0 & 0 & 0 & 0.2 & 280 & 0.3 & 280 & 0.4 & 280 & 0.5 & 280 & 0.6 & 280 & 0.8 & 280 \\
\hline 3 & 0 & 0 & 0 & 0 & 0 & 0 & 0.5 & 300 & 0.6 & 320 & 0.6 & 320 & 0.6 & 300 & 0.8 & 290 \\
\hline 4 & 0 & 0 & 0.3 & 350 & 0.5 & 360 & 0.5 & 360 & 0.6 & 90 & 0.7 & 320 & 0.7 & 320 & 0.7 & 80 \\
\hline 5 & 0 & 0 & 0.4 & 360 & 0.5 & 60 & 0.6 & 55 & 0.6 & 90 & 0.7 & 80 & 0.7 & 80 & 0.8 & 75 \\
\hline 6 & 0 & 0 & 0 & 0 & 0.6 & 60 & 0.7 & 45 & 0.7 & 80 & 0.7 & 75 & 0.7 & 60 & 0.9 & 60 \\
\hline 7 & 0 & 0 & 0 & 0 & 0 & 0 & 0.6 & 35 & 0.8 & 70 & 0.7 & 70 & 0.8 & 45 & 1 & 50 \\
\hline 8 & 0 & 0 & 0 & 0 & 0 & 0 & 0 & 0 & 0.9 & 70 & 0.8 & 60 & 0.8 & 35 & 1.2 & 43 \\
\hline 9 & 0 & 0 & 0 & 0 & 0 & 0 & 0 & 0 & 0.9 & 60 & 0.9 & 50 & 0.9 & 25 & 1.1 & 30 \\
\hline 10 & 0 & 0 & 0 & 0 & 0.6 & 60 & 0.7 & 45 & 0.7 & 80 & 0.7 & 75 & 0.7 & 60 & 0.9 & 60 \\
\hline
\end{tabular}

Table 2: Bathymetry input data along the pipeline route

\begin{tabular}{|c|c|c|c|c|c|c|c|c|c|c|c|c|c|c|c|c|c|}
\hline $\mathrm{Y} / \mathrm{X}$ & 1 & 2 & 3 & 4 & 7 & 8 & 9 & 10 & $\mathrm{Y} / \mathrm{X}$ & 1 & 2 & 3 & 4 & 7 & 8 & 9 & 10 \\
\hline 1 & 0 & 0 & 0 & 0 & 12.5 & 17.1 & 17.5 & 12.5 & 6 & 0 & 0.5 & 4 & 7 & 30 & 34.5 & 38 & 30 \\
\hline 2 & 0 & 0 & 5 & 2.5 & 22 & 24 & 26 & 22 & 7 & 0 & 0 & 0 & 5 & 24.5 & 30.5 & 40 & 24.5 \\
\hline 3 & 0 & 2 & 6 & 10 & 30 & 31 & 34 & 30 & 8 & 0 & 0 & 0 & 0 & 35 & 43 & 45.5 & 35 \\
\hline 4 & 0 & 6 & 9.5 & 16 & 41 & 42 & 43 & 41 & 9 & 0 & 0 & 0 & 0 & 36 & 40 & 45 & 36 \\
\hline 5 & 0 & 4 & 8 & 13 & 42 & 42 & 45 & 42 & 10 & 0 & 0 & 0 & 0 & 25 & 30 & 34 & 25 \\
\hline
\end{tabular}

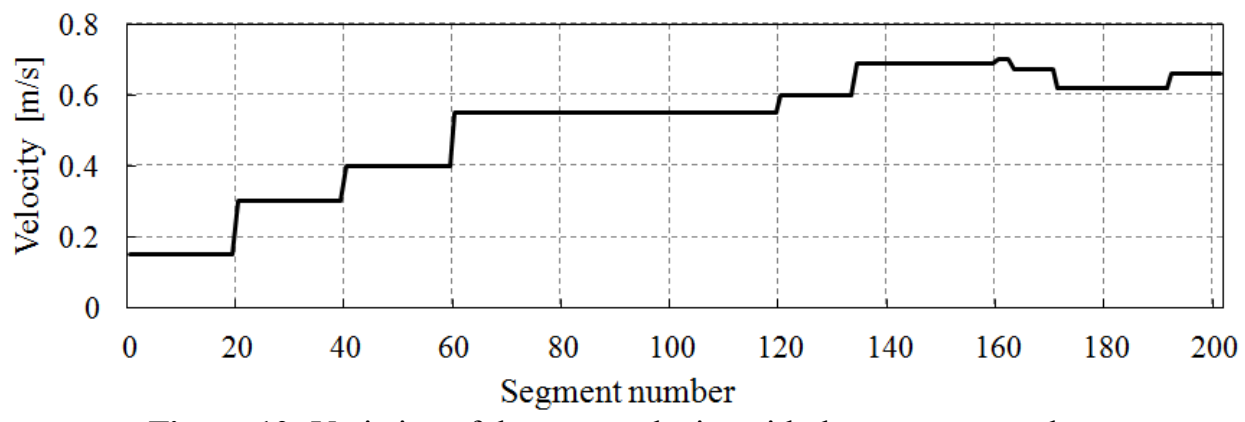

Figure 10: Variation of the wave velocity with the segment numbers 


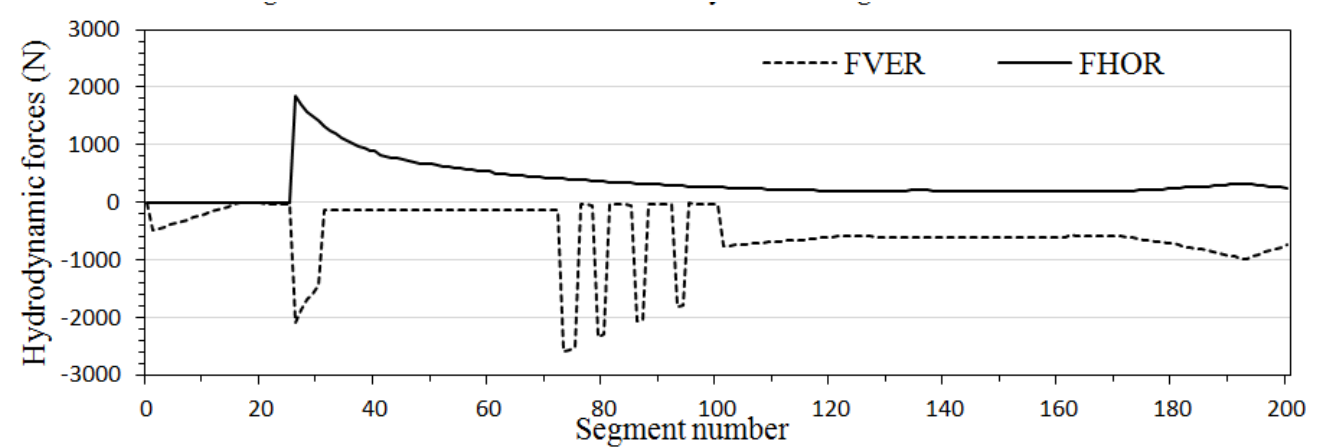

Figure 11: Variations of the hydrodynamic forces along the pipeline

The variation of the wave velocities along with pipe segment (200 segments were considered) are shown in Figure 10. The maximum and minimum wave velocities were $0.70 \mathrm{~m} / \mathrm{s}$ and $0.15 \mathrm{~m} / \mathrm{s}$. With the implementation of the SUPLID program, the vertical and horizontal forces affecting on the pipeline segments were calculated. The program yielded the pipeline segments with different structural cross sections such that 125 meters of the pipeline was designed as a buried segment because of the environmental factors.
After this segment, partition, pipeline was localized on the sea bed. The horizontal (FVER) and vertical forces (FHOR) exerted on the pipeline are shown in Figure 11. Particularly, for the first 26 segments horizontal exerted forces are zero resulted that pipeline is buried under the seabed. Between the segments 80 and 100, the deviations of the vertical forces exerted on the pipeline are directly influenced by the design configuration of the pipeline and the variable soil properties along the pipeline route.

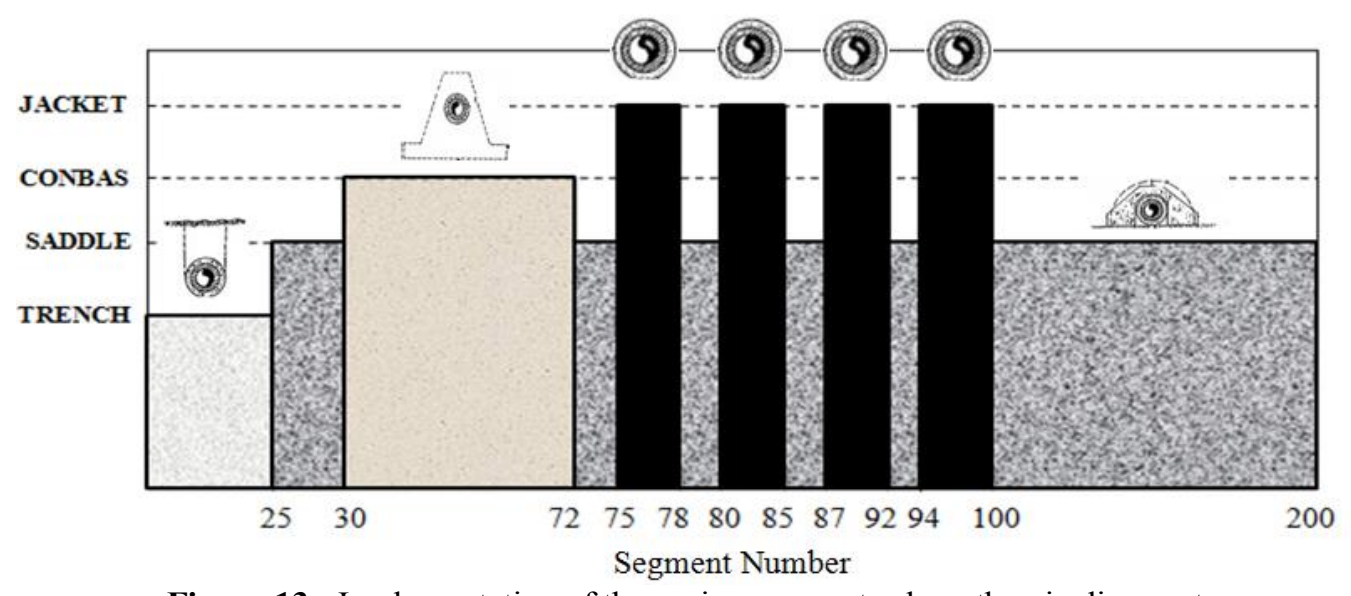

Figure 13: Implementation of these pipe segments along the pipeline route

The diameter and type of the pipeline sections changes continuously to preserve the stability under the environmental conditions. To obtain a reliable pipeline system with minimal deflection and deformations, four distinct pipe section types were considered as trench, saddle, conbas and jacket type sections. The implementation of these pipe sections along the pipeline route is shown in Figure 13.

\section{CONCLUSION}

In this study, the SUPLID program is introduced as a beneficial tool for performing the stability design of the wastewater pipelines considering water-pipe-soil interaction .In the first phase of the program routine, pipe stability is analyzed by considering the submergence of the pipeline under the effects of hydrodynamic and hydrostatic forces. For this, program also evaluates the applicability of the concrete weights if necessary. Later on, program routine tries to analyze the horizontal stability of the pipeline under the influence of horizontal forces and soil friction. An iterative solution procedure is also introduced by the program code because if the pipe diameters are increased for the horizontal stability design, consecutively, hydrodynamic forces are also changed. This study demonstrated that using a computer program for designing the wastewater submarine pipeline systems is beneficial for a design engineer for eliminating the time consuming analysis and implementing a try-error procedure for 
several route alternatives. This study also demonstrated that, the wastewater pipeline design can be accomplished without using a expensive commercial software but a well written program for performing the stability and hydraulic analysis can be sufficient for having a reasonable design performance and may lead the design engineer for the final design.

\section{REFERENCES}

[1]. Ajeesh, M. V., 2015. "Hydrodynamic Analysis Of An Inverted Catenary Coldwater Pipelıne Of A Lttd Plant", 34th International Conference on Ocean, Offshore and Arctic Engineering, ASME.

[2]. Akpan, P.U., 2015. "Modelling and Transient Simulation Of Water Flow In Pipelines Using Wanda Transient Software", Ain Shams University Ain Shams Engineering Journal.

[3]. Bleninger, T., Jirka G.H. , 2005. User's Manual for Corhyd: An Internal Diffuser Hydraulics Model, Version 1.0, University of Karlsruhe.

[4]. Chakrabarti, S.K., 1987. Hydrodynamics of Offshore Structures, Computational Mechanics Publications, Springer-Verlag, Berlin.

[5]. Coastal Engineering Manual (CEM), 2006.Chapter 1, Water Wave Mechanics, Part 2, U.S. Army Coastal Engineering Research Center.

[6]. Cokgor, S.and Avci, I., 2001. "Hydrodynamic Forces on Partly Buried Tandem Twin Pipelines in Current", Ocean Engineering , 28:1349-1360.

[7]. Gökkuş, Ü., 1995. "Computer-Aided Design of Submarine Pipelines", Water Science and Technology, 233-241.

[8]. Grace, R.A., 2009. Marine Outfall Construction Background, Techniques, and Case Studies, American Society of Civil Engineers, http:// dx.doi.org/10.1061/9780784409848.

[9]. Ludwig, R.G., 1998. Environmental Impact Assessment, Sitting and Design of Submarine Outfalls, An EIA Guidance Document.

[10]. Rossman,L.A.,1999.Computermodels/EPAN ET.In:Mays, L.(Ed.),Water Distribution
Systems Handbook. McGraw-Hill companies, Inc., New York, NY (Chapter 12).

[11]. Sümer, B.M., Fredsoe, J., 1997., Hydrodynamics around Cylindrical Structures, Advanced Series on Ocean Engineering, vol. 12. World Scientific.

[12]. Wu, Y. T. and Riha, D.S., 2000. "8th American Socieity of Civil Engineer Special Conference on Probabilistic Mechanics and Structural Reliability", American Soceiety of Civil Engineer, ASCE, 312-325.

[13]. Yalçın, Y. , Çevik, E. , 2009., Coastal Engineering, Beta Publishing., Istanbul. (in Turkish)

[14]. Yeksayev, A., 2016. Pipeline Networks EModelling Based On Citycom Technology: Experience Of Industrial Implementation For Large Water-Supply Systems, 12th Inter. Conference on Hydroinformatics. 